\title{
Anatomical correctness
}

\author{
Andrew Verniquet, MD, FRCPC
}

Received: 22 March 2020/Accepted: 23 March 2020/Published online: 23 April 2020

(c) Canadian Anesthesiologists' Society 2020

\section{To the Editor,}

I read with interest the article by Echaniz et al. regarding their anatomical study of an ultrasound-guided maxillary nerve block using a suprazygomatic approach. ${ }^{1}$ Several aspects of their study warrant comment and clarification. As with any anatomical study, the correct identification of the structures seen or imaged is important. The images in their Fig. 3B, C, and D, all appear to be similar imaging planes with the transducer in the infrazygomatic area with the superficial hyperechoic structure with posterior acoustic shadowing posterior to the maxilla identified by these authors and others ${ }^{2,3}$ as the sphenoid bone. Nevertheless, imaging from this position shows parts of the mandible in the image, which also appears as a superficial hyperechoic structure with posterior shadowing. A simple way to discern that the structure is the mandible is to move the mandible while imaging. The greater wing of the sphenoid can easily be imaged with the transducer in the suprazygomatic area but not from the infrazygomatic area. When doing this, the lateral pterygoid plate of the sphenoid bone can be seen in the far field as a linear horizontal hyperechoic structure ${ }^{4}$ with the infrazygomatic approach.

It is important to understand the orientation of the imaging plane and the needle direction when using the suprazygomatic approach. The upper part of the ultrasound image represents superficial, inferior, and lateral structures while the lower aspect represents deep, medial, and superior structures. The needle is inserted in a medial, inferior, and posterior direction. Assuming that the linear

A. Verniquet, MD, FRCPC ( $₫)$

GB Cross Memorial Hospital, Clarenville, NL, Canada

e-mail: andrewverniquet@hotmail.com hyperechoic structure seen at the bottom of the image is the superior part of the lateral pterygoid plate, when the needle is seen in the imaging plane the tip must be inferior to this area and the needle would most likely anchor into the lateral pterygoid plate and not into the nasal bones (which form the bridge of the nose) as suggested by the authors.

Another aspect of the Echaniz et al. paper that needs clarification relates to the distance measurements from their elderly adult female cadavers that appear to be very similar to those reported by Sola et al. ${ }^{2}$ in live infants; it is uncertain how these would correlate with a live adult.

Finally, one has to wonder if the use of ultrasound adds to the safety of the technique. The neural structures are not visible and the area is highly vascularized. While colour Doppler can be used to identify vessels, there is a considerable blind spot when using an out-of-plane ultrasound approach due to the interposition of the zygomatic bone. In addition, the maneuvers normally used to track the needle tip-transducer angulation, transducer movement, and needle angulation step-down technique are not effective. The authors used an $8-13 \mathrm{MHz}$ linear transducer for their study. Nevertheless, as the technique largely depends on bony landmarks, and the soft tissue images are poorly defined, and an imaging depth of at least $3 \mathrm{~cm}$ is needed (to identify the lateral pterygoid plate), the use of a lower frequency curvilinear probe may produce better image quality in adults.

Conflicts of interest None.

Funding statement None.

Editorial responsibility This submission was handled by Dr. Hilary P. Grocott, Editor-in-Chief, Canadian Journal of Anesthesia. 
Editor's note The authors of the article: Can J Anesth 2020; https:// doi.org/10.1007/s12630-019-01481-x, respectfully declined an invitation to submit a reply to the above letter due to limitations related to current pandemic conditions.

\section{References}

1. Echaniz G, Chan V, Maynes JT, Jozaghi Y, Agur A. Ultrasoundguided maxillary nerve block: an anatomical study using the suprazygomatic approach. Can J Anesth 2020; 67: 186-93.

2. Sola C, Raux O, Savath L, Macq C, Capdevila X, Dadure C. Ultrasound guidance characteristics and efficiency of suprazygomatic maxillary nerve blocks in infants: a descriptive prospective study. Pediatr Anesth 2012; 22: 841-6.

3. Bouzinac A, Tournier JJ, Dao M, Delbos A. Ultrasound-guided maxillary nerve block in adults: feasibility and efficiency for postoperative analgesia after maxillary osteotomy. Minerva Anestesiol 2014; 80: 860-1.

4. Alfaro-de la Torre P, Pie SB, Perez MF, Gonzalez-Arnay E. Ultrasound-guided maxillary nerve block via the pterygopalatine fossa: anterior versus posterior infrazygomatic approach. Reg Anesth Pain Med 2019; https://doi.org/10.1136/rapm-2018100077.

Publisher's Note Springer Nature remains neutral with regard to jurisdictional claims in published maps and institutional affiliations. 